\title{
未破裂無症候性脳動脈瘤の治療指針
}

糟谷 英俊, 恩田 英明, 竹下 幹彦
岡田 芳和, 氏家 弘, 堀 智勝

\section{Management Decisions in Patients with Asymptomatic Unruptured Aneurysm}

Hidetoshi KasuYa, M.D., Hideaki Onda, M.D., Mikihiko TaKeshita, M.D., Yoshikazu Okada, M.D., Hiroshi UsIIE, M.D., and Tomokatsu Hori, M.D.

Department of Neurosurgery, Tokyo Women's Medical University, Tokyo, Japan

Summary: Management decisions in patients with asymptomatic unruptured aneurysms require accurate assessment of the risk: benefit ratio of various treatment options compared to the natural history of the disease. We analyzed the risks associated with aneurysmal surgery and risk of rupture in 84 patients with asymptomatic unruptured aneurysms experienced between 1990 and 1999 at Tokyo Women's Medical University. Thirty-six aneurysms were located at the internal carotid, 25 at the anterior cerebral, 35 at the middle cerebral, and 8 at the vertebro-basilar artery. Sixty-nine aneurysms in 58 patients were treated surgically (60 aneurysms were clipped, 8 coated, and one embolized). Permanent mortality occurred in 6 patients, a major cause of which was cerebral infarction due to perforator vessel injury. Presenting symptoms of intracerebral hematoma and multiple lacunar infarctions were associated in 2 patients. One patient was over 80 years old. A follow-up study was done with 25 aneurysms in 25 patients. The median follow-up time was 3.2 years (0.1-8.6 years). There were 6 episodes of hemorrhage, giving an average annual rupture incidence of $7.5 \%$. Five of these bleeding episodes were fatal (mortality: 83\%). Four aneurysms were $>11 \mathrm{~mm}$. In conclusion, the relatively high incidence of surgical morbidity depended on perforator vessel injury. The patient's age and presenting symptoms of cerebrovascular disease seemed to be associated with increased operative morbidity. The high risk of rupture followed by death was noted in a follow-up period in patients with asymptomatic unruptured aneurysm.

\author{
Key words: \\ - asymptomatic \\ - unruptured \\ - aneurysm \\ - morbidity \\ - rupture
}

Surg Cereb Stroke

(Jpn) 29: 282-285, 2001

\section{はじめに}

最近の報告では脳動㟲瘤の保有率は約 $5 \%$ と考えられて 抢り 45)10), 脳ドックやMRAの普及により, 未破裂無症 候性の脳動脈瘤が発見される場合が多くなった。脳動脈瘤 が破裂したさいの死亡率が高いため ${ }^{8}$ ，これを未然に防ぐ
ための治療が、般的になりつつある。しかし, 脳動脈瘤の 出血率は考えられていたより低ぐ，治療は扔ろかスクリ 一ニングさえ疑牌視する意見もある2〉.今回，未破裂無症 候性脳動脈瘤に対古る治療指針に役立てるため, 当院に人 院した患者の治療内容と, 経過観察群ではその後の経過に ついて検討した。 
対象，方法

1990年以降 1999 年までに診断された未破裂無症候性脳 動脈瘤について検討を加えた。瘤の圧迫による脳神経症状 や頭痛を呈している症例は除いた。また，破裂脳動脈瘤に 伴う多発性脳動脈瘤と脳動静脈奇形に伴う脳動脈瘤も除い た。incidentalにみっかった脳動脈瘤の治療成績と治療し なかった症例についてはできる限り追跡調査を行い，脳動 脈瘤の出血率を算定した。検討は主にカルテと手術記録に 基づいた。また，追跡調查は外来通院中の症例については カルテ拀よび主治医から，そうでない症例では電話によっ た。

対象は 84 例 (男 38 例, 女 46 例)で, 年齢は 34-82歳, 平 均 56 歳であった。多発性動脈瘤は 19 例で, 2 個あるもの は 18 例，3個あるものは 1 例であった。対象となった脳動 脈瘤は 104 個である。脳動脈瘤部位は Table 1 に示すごと くであった。脳動脈瘤の最大径は，3-10 $\mathrm{mm}$ が 89 個， 11-20 mmは14個， $21 \mathrm{~mm}$ 以上は 1 個であった。原疾患 は, 脳ドックで発見されたもの30例, 頭痛精査でわかっ たもの 20 例, 脳血管障害 14 例 (脳梗塞 9 例, 脳出血 5 例), 脳腫瘍 4 例 (下垂体腫瘍 3 例, 前庭神経シュワノーマ 1 例), 多発性囊胞腎 3 例, 随膜炎, 副鼻腔炎, 家族歴, 意識消失 発作，めまいがそれぞれ2例，その他が 3 例であった，手 術難易度の高くない脳動脈瘤で, 合併症のない症例にはな るべく開頭術を钓めた。

\section{結＼cjkstart果}

手術に至った症例数は58で, 69個の脳動脈瘤に対し， 63 回の開頭術, 1 回の embolizationが行われた。平均 54.6 歳で, clippingは 60 個に, coatingは 8 個に行われた。術 者は複数で, 専門医前の者も含まれている。手術合併症は, 穿通枝障害 12 例, 脳挫傷 4 例, 硬膜下水腫 4 例, 全身㽷 孬発作 3 例, 硬膜外血腫 1 例, 動眼神経麻疩 1 例, 無息症 1 例, 脳炎 1 例, 一過性脳虚血発作 1 例, 中大脳動脈閉塞 1 例の 29例であった(重複例あり)。手術が原因の死亡は なかった。退院時に手術に起因する合併症状があったのは 11 例で, 記銘力障害 4 例, 片麻疩 6 例, 動眼神経麻瘒 1 例 であった (surgical morbidity: 17.4\%, 11/63)。この原因と しては, 穿通枝障害 8 例, 脳挫傷 1 例, 動眼神経麻痺 1 例, 動脈閉塞 1 例であった。脳動脈瘤の部位は前交通動脈瘤 4 例, 中大脳動脈瘤 3 例, 内頚動脈瘤 4 例であり, 動脈瘤の 大きさは $10 \mathrm{~mm}$ 以下が 9 例であった。これらの症例のう ち麻瘏などのため自宅退院が難しく、リハビリのため転院 となったのは 4 症例であり，強い記銘力障害を残して自宅 退院したのは 2 例であった。 permanent morbidity は9.5\% (6/63)であった。このうち，2 例は脳出血のため行った脳
Table 1 Location of 104 asymptomatic unruptured aneurysms

\begin{tabular}{cc}
\hline Location & No. of aneurysms \\
\hline Internal Carotid & 36 \\
Posterior communicating & 23 \\
Anterior choroidal & 2 \\
Ophthalmic & 7 \\
Cavernous & 4 \\
Anterior Cerebral (AC) & 25 \\
Anterior communicating & 23 \\
AC distal & 2 \\
Middle Cerebral & 35 \\
Basilar Vertebral & 8 \\
Basilar tip & 6 \\
Posterior inferior cerebellar & 1 \\
Posterior cerebral & 1 \\
\hline
\end{tabular}

血管撮影でみつかった脳動脈瘤に対し手術が行われ，強い 症状を残寸に至った。また，关のうちの1例は，多発性脑 挭塞も合併していた。また，1例は 82 歳ときわめて高齢 であった (Table 2).

·方，経過観察した脳動脈瘤は 36 個で，34 症例である (手術症例と重なっている症例あり)。5脳動脈瘤は他院で 治療を受けた。6脳動脈瘤は追跡できなかった。このため 25 脳動脈瘤 (25 症例) を対象とした。追跡開始時は 41-81 歳で, 平均 54.6歳, 追跡期間は 1-105力月で, 平均 38力 月であった。 $10 \mathrm{~mm}$ 以下は 18 個， $11 \mathrm{~mm}$ 以上は7個であ つた。前者のうち 2 個が破裂，後者は 4 個が破裂した。内 頚動脈瘤 6 例中出血なく, 前交通動脈瘤 6 例中 2 例, 中大 脳動脈瘤 7 例中 1 例出血, 脳底動脈瘤 4 例中 2 例が出血 $L$ た。前交通動脈瘤の 1 例は脳血管撮影中にくも膜下出血を 起こし粲急手術を行った。この症例以外は治療を受けるこ となく死亡していた。これらの詳細はTable 3に示した。 年平均の破裂率は $75 \%$ であった。

\section{考察}

手術成績の結果は mortality 0\%, morbidity $17.7 \%$ (permanent morbidity: 9.5\%)とこれまでの内科系医による大 規模研究とほぼ司じ結果となっている3111)。先の未破裂動 脈瘤の他施設協同研究では治療後 1 力月で mortality, morbi dity 合わせた数值が $17.5 \%$ であった ${ }^{3)}$ 。脳神経外科 医の報告によれば， mortality，morbidity それぞれ，1.0\%， $4.1 \%{ }^{7)}, 0 \%, 65 \%^{17)}$ である。また， $10 \mathrm{~mm}$ 以下の動脈瘤 ではともに $0 \%$ とする報告もある ${ }^{14)}$ 。各施設の morbidity の差は施設の技術的な問題とばかりは考えにくく， Raaymakerらは，脳神経外科医は往々にして手術成績を よく解釈しがちであると述べている ${ }^{11)}$ ，正確に把握する ためには第:者的な立場にある研究者が分析を行う必要も 
Table 2 Summary of cases with permanent surgical morbidity

\begin{tabular}{|c|c|c|c|c|c|c|c|c|}
\hline Case & Age & Sex & Location & Size $(\mathrm{mm})$ & $\begin{array}{l}\text { Admission } \\
\text { period (days) }\end{array}$ & $\begin{array}{l}\text { Symptoms } \\
\text { led to studies }\end{array}$ & $\begin{array}{l}\text { Surgical complications } \\
\text { Symptoms }\end{array}$ & Cause \\
\hline 1 & 55 & $M$ & AcomA & 8 & 51 & $\mathrm{ICH}$, infarction & dementia & perforator injury \\
\hline 2 & 64 & $M$ & AcomA & 7 & 44 & $\mathrm{ICH}$ & dementia & perforator injury \\
\hline 3 & 43 & $F$ & AcomA & 7 & 40 & headache & memory disturbance & perforator injury \\
\hline 4 & 45 & $F$ & MCA & 7 & 124 & headache & $\begin{array}{l}\text { hemiparesis } \\
\text { aphasia }\end{array}$ & trunk occlusion \\
\hline 5 & 82 & $F$ & ICAntCho & 12 & 78 & brain dock & Abbie syn & perforator injury \\
\hline 6 & 48 & $M$ & MCA & 30 & 22 & headache & hemiparesis & perforator injury \\
\hline
\end{tabular}

AcomA: anterior communicating artery; MCA: middle cerebral artery; ICAntCho: internal carotid anterior choroidal artery; ICH: intracerebral hematoma

Table 3 Aneurysms ruptured in a follow-up period

\begin{tabular}{lcclclll}
\hline Case & Age & Sex & Location & Size $(\mathrm{mm})$ & $\begin{array}{c}\text { Concurrent } \\
\text { disease }\end{array}$ & $\begin{array}{c}\text { Period between diagnosis } \\
\text { and rupture }\end{array}$ & Outcome \\
\hline 1 & 71 & M & AcomA & 12 & infarction & 7 year 3 mon & dead \\
2 & 62 & F & BAtip & 15 & brain tumor & 4 year & dead \\
3 & 51 & M & MCA & 15 & renal failure & 4 mon & dead \\
4 & 45 & M & BAtip & 20 & renal failure & 4 mon & dead \\
5 & 50 & M & MCA & 5 & mucocele & 4 year 7 mon & dead \\
6 & 49 & M & AcomA & 5 & brain dock & 1 mon & good \\
\hline
\end{tabular}

AcomA: anterior communicating artery; BA: basilar artery; MCA: middle cerebral artery

あろう。今後は高次機能なども調べていく必要がある。多 くは転州に影響を与えるものではなかったにせよ minor complicationの多いのも事実である12). mortality は幸い 当院では $0 \%$ であったが，当院退院後，他院で治療を受け た 1 例が，治療がもとで死亡している。けっして $0 \%$ では ないことを念頭に㧍いて扔く必要がある。

今回, morbidityを高くしていたのは, 患者の背景がさ まざまで, 既存の脳神経疾患を有する症例が少なからず含 まれていたためもある。他の脳血管障害を合併する未破裂 動脈瘤の転帰はよくない ${ }^{9)}$ 17) 。この原因として, 脳の手術 中圧迫や－時遮断に起因するもの，穿通枝棵塞によるもの が報告されている。手術中操作で注意しても防ぐのが困難 と思われる例もある ${ }^{9)}$.また, かなりの高齢者も手術が行 われており，これも morbidityを高めた一因とい元る。先 の未破裂脳動脈瘤の大嫢模研究でも, 年齢の及が, 手術に よる合併症と関係していた ${ }^{3)}$. 高齢者は脳動脈瘤手術によ る恩恵はきわめて少なく，70歳代の手術で期待される延 命は 0.6 歳である ${ }^{1)}$ 。そのう元, 高齢者では脳動脈瘤を有 する率が高く，出血率は低い $\left.{ }^{4)} 13\right\rangle$. 高齢者に対する治療は きわめて慎重でなければならない。もうひとつ, 手術の成 績に関倿するのは脳動脈瘤の大きさと部位である ${ }^{6) 14}$. 大 きい脳動脈瘤, posterior circulationの脳動脈瘤は risk は
高い。Khanna $ら^{6)}$ は，年齢，大きさ，動脈瘤の部位によ りダレード分類を行った。年齢は 40 歳未满を 0 点, $40-60$ 歳を 1 点, 60 歳以上を 2 点, 動脈瘤の大きさは, $10 \mathrm{~mm}$ 以下を 0 点, 11-25 mm を 1 点, $25 \mathrm{~mm}$ 以上を 2 点, 動脈 瘤の部位によって0-2点とした。0点であるグレード 0 は 6\%，6点であるグレード 6 は $66.6 \%$ の morbidityが予想さ れるとしている。

手術手技に関しては，穿通枝障害が問題となることが多 かった ${ }^{12)}$ 15) . 最近は静脈損傷による症状が問題とされて いるが，カルテと手術記録によれば静脈損傷と考えられる 症例はなかった。脳動脈瘤手術に扔いて，完全に瘤を clip するためには，どうしても穿通枝を閉塞せざるを得ない例 は存在する。脳底動脈瘤はいうまでもなく, 前交通動脈瘤 の穿通枝障害に扔いても, 社会の一線で活躍している場合, それまでの社会生活が破綻することもありえよゔ ingの意義については明らかとされてはいないが，われわ れの追跡した 8 症例では破裂症例は認めていない(追跡期 間： 5 力月-2年 9 力月)。穿通枝が温存できないようなら ば, coatingに切り替える角気を持っ必要もあろう。また, アプローチの選択も重要である，前交通動脈瘤では，前向 きであれば，穿通枝はpterional で問題となることはまず ないであろうが，穴机以外ではどうしても blind となって 
しまう。ちなみにわれわれの症例のすべては pterional approachで行われていた。今回の症例には coil embolization は 1 例のみに用いられているが, 症例によっては coil を選んだほうがよい場合があることに異論はなからう。

今回の経過観察群 25 例での出血は6例にあった。追跡 期間は 0.1 から 8.6 年で，年間の出血率は $7.5 \%$ であった。 これはこれまでの報告と比べきわめて高い. $10 \mathrm{~mm}$ 以上 の脳動脤瘤は破裂しやすいとされるが3)，われわれの症例 も破裂の 6 例中 4 例が $10 \mathrm{~mm}$ 以上であった。 Wieber ら ${ }^{16)}$ は，破裂する動脈瘤はほとんどすべて $10 \mathrm{~mm}$ 以上で，破 裂動脈瘤の平均の大きさが $7.5 \mathrm{~mm}$ であるのは，破裂した のち，動脈瘤が小さく造影されるためであると考察してい る、動脈瘤の大きさのみが破裂を予想する因けである゙と する報告, $10 \mathrm{~mm}$ 以は破裂率がきわめて低く，年 $0.7 \%{ }^{13)}$ あるいは， $0.05 \%^{3)}$ との報告がある。脳動脈瘤の部 位では，脳底動脈瘤が破裂しやすいとの報告は、致してい るが 4) 13〉，その他は・定しない。

くも膜下出血の死亡率は・般的には50\%と考えられて いるが11)12), 今回のわれわれの症例では, 長期 follow d れ破裂した 5 例は，全例治療を受けずに死亡していた。久 山町の報告では発症 30 Пでの死亡率は $61 \%$ であり，䛊診 されていることも多かっだ， 、後, prospectiveな研究 が行われれば，破裂動脈瘤の正確な出血率とともにそのさ いの死亡率も明らかになるであろう。

今回の検討では治療群, 経過観察群の両者について, 死 亡率に限机ば，治療は有用であったといえる。今後は，1） 出血しやすい脳動脤瘤をいかに抽出していくか，2）手術 のリスクの高い患者をいかに手術適応から除くかという二 つの問題が，治療の效率を高めるうえで重要と考える。高 齢者は，出血のリスクが低く，手術のリスクが高いため, その治療方針は明確であるが, $10 \mathrm{~mm}$ 以上の脳動脈瘤は, 破裂のリスクが高く，手術のリスクも高いため，治療方針 決定にはそれ以外の要因も含めて慎重に行う必要がある。 Khanna ${ }^{6)}$ のように手術リスクのグレードを用いること も・法かと考える.われわれは現在, 脳動脈瘤の遺伝了解 析を行って㧍り，脳動脈瘤やその出血のリスクを遺伝学的 に解明することも将来可能になると考えている。

\section{結 論}

1.未破裂無症候性動脈瘤の手術合併症は約 1 割であり, 特に穿通枝障害が問題であった。

2. 他の脳血管障害による症状を呈する症例, 高齢者, 大 きな動脈瘤の手術のリスクが高い。

3. 経過観察中の症例に biasはあるものの, 脳動脈瘤の出 血率，死亡率はきわめて高い。

\section{文献}

1) Chang HS, Kirino T: Quantification of operative benefit for unruptured cerebral aneurysms: a theoretical approach. J Neurosurg 83: 413-420, 1995

2) Crawley F, Clifton A, Brown MM: Should we screen for familial intracranial aneurysm? Stroke 30: 312-316, 1999

3) The international study of unruptured intracranial aneurysm investigators: Unruptured intracranial aneurysms risk of rupture and risks of surgical intervention N Engl J Med 339: 1725-1733, 1998

4) Iwamoto H, Kiyohara $\mathrm{Y}, \mathrm{F}$ ujishima $\mathrm{M}$, et al: Prevalence of intracranial saccular aneurysms in a Japanese community based on a consecutive autopsy series during a $30-$ year observation period. The Hisayama Study. Stroke 30: 1390-1395, 1999

5) Juvela S, Porras M, Heiskanen O: Natural history of unruptured intracranial aneurysms: a long-term follow-up study. J Neurosurg 79: 174-182, 1993

6) Khanna RK, Malik GM, Qureshi N: Predicting outcome following surgical treatment of unruptured intracranial aneurysms a proposed grading system. J Neurosurg $\mathbf{8 4}$ 49-54, 1996

7) King Jr JT, Berlin JA, Flamm ES: Morbidity and mortality from elective surgery for asymptomatic, unruptured, intracranial aneurysms: a meta-analysis J Neurosurg 81: 837-842, 1994

8) Kiyohara $Y$, Ueda $K$, Hasuo $Y$, et al: Incidence and prognosis of subarachnoid hemorrhage in a Japanese rural community. Stroke 20: 1150-1155, 1989

9）松本勝美, 赤木功人, 安部倉信, 活加：脳虚血病変精查中 に発見された未破裂脳動脈瘤の治療選択上合併症。脳神経外 科 28: 699-703, 2000

10) Nakagawa $T$, Hashi $K$ : The incidence and treatment of asymptomatic, unruptured cerebral aneurysms J Neurosurg 80: 217-223, 1994

11) Raaymakers TWM, Rinkel GJE Limburg $M$, et al: Mortality and morbidity of surgery for unruptured intracranial aneurysms. A meta-analysis. Stroke 29: 15311538, 1998

12) Rice BJ, Peerless SJ, Drake CG: Surgical treatment of unruptured aneurysms of the posterior circulation. J Neurosurg 73: 165-173, 1990

13) Rinkel GJE, Djibuti M, Alga A, et al: Prevalence and risk of rupture of intracranial aneurysms. A systematic review. Stroke 29: 251-256, 1998

14) Solomon RA, Fink ME, Pile-Spellman J: Surgical management of unruptured intracranial aneurysms. J Neurosurg 80: 440-446, 1994

15）牛越 聡, 伊藤文生, 齋藤久寿, ほか：未破裂脳動脈瘤の 外科治療. 脳卒巾の外科 23: 429-434, 1995

16) Wiebers DO, Whisnant JP, Sundt Jr TM, et al: The significance of unruptured intracranial saccular aneurysms. J Neurosurg 66: 23-29, 1987

17) Wirth FP, Laws ER, Piepgrass D, et al: Surgical treatment of incidental intracranial aneurysms. Neurosurgery 12: $507-511,1983$ 